\title{
Effects of climatic perturbations on the equilibrium-line altitude, West Greenland
}

\author{
WALTER AMBACH \\ Institut für Medizinische Physik, Universität Innsbruck, A-6020 Innsbruck, Austria
}

\begin{abstract}
Perturbation analysis is applied to the heat balance at the EGIG line (West Greenland) with respect to climatic changes. The shift of the equilibriumline altitude is obtained for perturbations of temperature, absolute humidity, cloudiness and annual accumulation. The total net ice ablation at the EGIG line increases by $45 \%$ with a perturbation of $+1 \mathrm{~K}$. Applying this figure to the entire ice sheet, the total ablation equals the total accumulation at a warming of $+2 \mathrm{~K}$, if refreezing of melt water is neglected.
\end{abstract}

\section{LIST OF SYMBOLS}

$A$

C

$c$

$H$

$h$

\section{INTRODUCTION}

The response of the Greenland ice sheet to the increase of $\mathrm{CO}_{2}$ and other atmospheric greenhouse gases is of recent interest (United States. Department of Energy, 1985). Climatic warming is closely connected with alterations in the heat balance and the shift of the equilibrium-line altitude. For the calculation of the shift of the equilibrium-line altitude due to climatic perturbations, a concept introduced by Kuhn (1981) was applied and adjusted to the conditions on the Greenland ice sheet (Ambach, 1989). The equilibrium-line altitude is essentially determined by the heat balance and the annual accumulation. At the equilibrium-line altitude, the heat of melting, supplied by the heat balance during the entire ablation season, equals the heat consumed for melting the annual accumulation including superimposed ice. The heat balance reads

$$
\tau_{0} H_{0}=k L c_{0} .
$$

$\tau$ is the number of ablation days, $H$ is the daily heat-flux density of melting averaged over the ablation period, $k$ is a factor related to the formation of superimposed ice, i.e. $1 \leq k \leq 5 / 3$ (Ambach, 1985), $L$ is the specific heat of melting and $c$ is the annual accumulation. The subscript zero refers to the steady-state conditions. $\tau, H$ and $c$ are functions of altitude obtained from measurements, and affected by climatic perturbations.

\section{CLIMATIC PERTURBATIONS}

In Kuhn's concept, the following climatic perturbations were introduced (Ambach, 1989):

Perturbations of air temperature $\left(\delta T_{\mathrm{a}}\right)$ with effects on $H$ and $\tau$.

Perturbations of the absolute humidity $\left(\delta \rho_{\mathrm{v}}\right)$ with effects on $H$.

Perturbations of the cloudiness $(\delta w)$ with effects on $H$.

Perturbations of the annual accumulation $(\delta c)$.

It is true that

$$
\begin{aligned}
\delta H & =\mu_{1} \delta T_{\mathrm{a}}+\mu_{2} \delta \rho_{\mathrm{v}}+\mu_{3} \delta w \\
\delta \tau & =\gamma \delta T_{\mathrm{a}} .
\end{aligned}
$$

The numerical values of $\mu_{1}, \mu_{2}, \mu_{3}$ and $\gamma$ are contained in previous work, when $\mu_{1}, \mu_{2}$ and $\mu_{3}$ were introduced as constants and $\gamma$ as a function of altitude (Ambach, 1989). The data are based on measurements of the heat balance, carried out at $1013 \mathrm{~m}$ a.s.l. during the International Glaciological Greenland Expedition (EGIG-1959; 
Ambach, 1963). Therefore, the results of the perturbation analysis are strictly valid for the EGIG line only.

Applying perturbation analysis, Equation (1) reads

$$
\begin{gathered}
{\left[\tau_{0}+\delta \tau+(\partial \tau / \partial z) \Delta h\right]\left[H_{0}+\delta H+(\partial H / \partial z) \Delta h\right]} \\
=k L\left[c_{0}+\delta c+(\partial c / \partial z) \Delta h\right] .
\end{gathered}
$$

This formulation contains the climatic perturbations $\delta \tau, \delta H, \delta c$ and the respective alterations $(\partial \tau / \partial z) \Delta h$, $(\partial H / \partial z) \Delta h$ and $(\partial c / \partial z) \Delta h$ due to the shift of the equilibrium line. Here $z$ is the altitude and $\Delta h$ is the shift of the equilibrium-line altitude.

\section{SHIFT OF THE EQUILIBRIUM-LINE ALTITUDE BY GLIMATIC PERTURBATIONS}

By applying the numerical values of $\partial T_{\mathrm{a}} / \partial z, \partial \rho_{\mathrm{v}} / \partial z$, $\partial w / \partial z, \partial \tau / \partial z$ and $\partial c / \partial z$ (Ambach, 1989), the shift of the equilibrium-line altitude is obtained for various perturbations (Table 1). The perturbation $\delta T_{\mathrm{a}}=+1 \mathrm{~K}$ has the biggest effect on the shift of the equilibrium-line altitude, since a rise in temperature leads to an increase in the heat-flux density of melting and a prolongation of the ablation period. Model calculations regarding the greenhouse effect have shown that in higher latitudes a warming of the lower atmosphere by a few degrees is likely (Manabe and Wetherald, 1975). The perturbation $\delta \rho_{\mathrm{v}}=+0.25 \mathrm{~g} \mathrm{~m}^{-3}$ corresponds to a $5 \%$ increase in
Table 1. Shift of the equilibrium-line altitude by climatic perturbations at the EGIG-line with $\partial c / \partial z=$ $0.55 \mathrm{~kg} \mathrm{~m}^{-2} \mathrm{~m}^{-1}$ and $\partial T_{\mathrm{a}} / \partial z=-0.0073 \mathrm{~K} \mathrm{~m}^{-1}$

relative humidity at $0^{\circ} \mathrm{C}$. The effects of changes in cloudiness are small and are therefore neglected in the following. The inconsiderable influence of cloudiness on the shift of the equilibrium-line altitude is due to the "radiation paradox" (Ambach, 1974). It implies that shortwave radiation decreases with increasing cloudiness, whereas longwave radiation increases so that a compensation effect occurs. Thus, the net radiation balance increases with cloudiness at an albedo larger than 0.66 and decreases at an albedo smaller than 0.66 . The perturbation $\delta c=+50 \mathrm{~kg} \mathrm{~m}^{-2}$ is approximately $10 \%$ of the annual accumulation at the present equilibrium-line altitude. All perturbations occur with mutual feed-back mechanisms. Very likely, an increase in temperature is coupled with an increase in absolute humidity, cloudiness and precipitation (Letréguilly and others, 1991a).
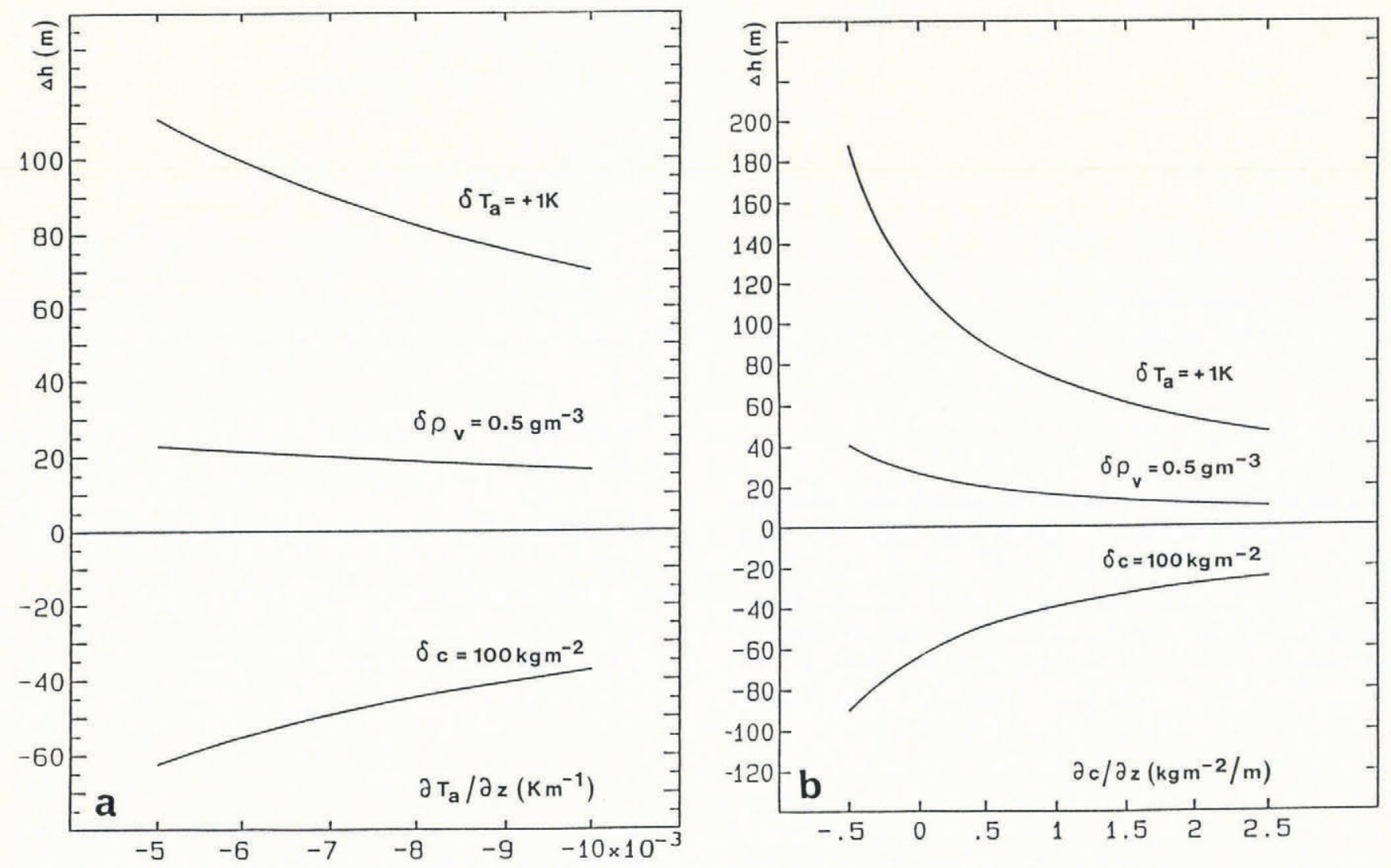

Fig. 1. a. Shift of the equilibrium-line altitude by perturbations $\delta T_{\mathrm{a}}=+1 \mathrm{~K}, \delta \rho_{\mathrm{v}}=+0.5 \mathrm{~g} \mathrm{~m}^{-3}$ and $\delta c=100 \mathrm{~kg} \mathrm{~m}^{-2}$ as a function of $\partial T_{\mathrm{a}} / \partial z$. b. Shift of the equilibrium-line altitude by perturbations $\delta T_{\mathrm{a}}=+1 \mathrm{~K}, \delta \rho_{\mathrm{v}}=+0.5 \mathrm{~g} \mathrm{~m}$ and $\delta c=100 \mathrm{~kg} \mathrm{~m}^{-2}$ as a function of $\partial c / \partial z$. 


\section{SHIFT OF THE EQUILIBRIUM-LINE ALTITUDE AND REGIONAL PARAMETERS}

The gradients $\partial T_{\mathrm{a}} / \partial z$ and $\partial c / \partial z$ are regarded as regional parameters. They are hardly influenced by climatic

Table 2. Shift of the equilibrium-line altitude for $\delta T_{\mathrm{a}}=$ $1 K$ and various combinations of $\partial c / \partial z$ and $\partial T_{\mathrm{a}} / \partial z$

\begin{tabular}{ccr}
$\partial c / \partial z$ & $\partial T_{\mathrm{a}} / \partial z$ & $\Delta h$ \\
$\mathrm{~kg} \mathrm{~m}^{-2} \mathrm{~m}^{-1}$ & $\mathrm{~K} \mathrm{~m}^{-1}$ & $\mathrm{~m}$ \\
& & \\
\hline & & 87.5 \\
+0.55 & -0.0073 & 102.5 \\
+0.55 & -0.0057 & 153.6 \\
-0.32 & -0.0073 & 211.4
\end{tabular}
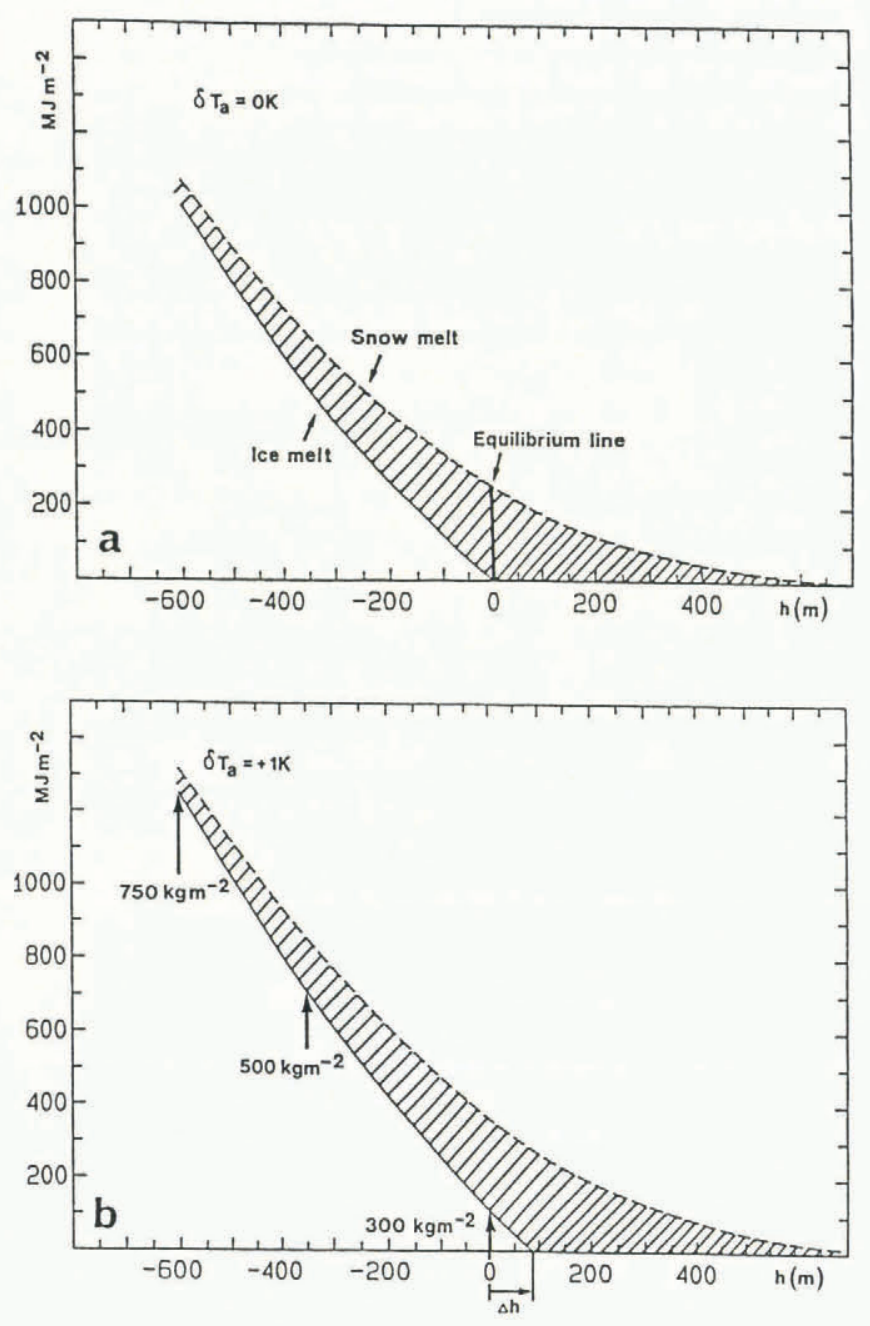

Fig. 2. a. Heat of melting as a function of altitude with $\delta T_{\mathrm{a}}=0$ for the entire ablation period. The dashed range corresponds to melting of snow and superimposed ice, the solid line corresponds to net ablation. $b$. As Figure $2 a$ with $\delta T_{\mathrm{a}}=+1 K$. Arrows indicate the increase in net ablation. changes. On the Greenland ice sheet, various ablation regimes occur, which are characterized by the values of $\partial T_{\mathrm{a}} / \partial z$ and $\partial c / \partial z$. In the following, the limiting values $-0.0073 \leq \partial T_{\mathrm{a}} / \partial z \leq-0.0057 \mathrm{Km}^{-1}$ and $-0.32 \leq \partial c / \partial z$ $\leq+0.55 \mathrm{~kg} \mathrm{~m}^{-2} \mathrm{~m}^{-1}$ are introduced. With these limiting values and with $\delta T_{\mathrm{a}}=1 \mathrm{~K}$, the shift of the equilibriumline altitude is shown in Table 2. Alterations of $\partial c / \partial z$ have a far stronger effect on $\Delta h$ than alterations of $\partial T_{\mathrm{a}} / \partial z$. Negative values of $\partial c / \partial z$ result in a particularly strong shift of the equilibrium-line altitude. Such negative values of $\partial c / \partial z$ on the Greenland ice sheet have been reported by Benson (1962). In Figure $1 \mathrm{a}$ and $\mathrm{b}$ the shift of the equilibrium-line altitude as a function of $\partial T_{\mathrm{a}} / \partial z$ and $\partial c / \partial z$ is compared for equal perturbations.

\section{ALTITUdINAL PROFILE OF NET ABLATION}

The heat of melting of snow, superimposed ice and glacier ice is represented as a function of altitude at the EGIG line without any perturbation (Fig. 2a). The difference between the dashed line and the solid line corresponds to the melting of snow and superimposed ice, whereas the solid line stands for the altitudinal profile of the heat of melting of glacier ice, corresponding to the net ice ablation. The net ice ablation starts at the equilibriumline altitude $(\Delta h=0)$ and increases towards the ice margin $(\Delta h=-600 \mathrm{~m})$ to about $3000 \mathrm{~kg} \mathrm{~m}^{-2}$. The nonlinear profile results from both the increase in the heatflux density of melting and the longer ablation period at lower altitudes.

For comparison, the altitudinal profile of the heat of melting was calculated for the perturbation $\delta T_{\mathrm{a}}=+1 \mathrm{~K}$ (Fig. 2b, dashed line). The corresponding shift of the equilibrium-line altitude is indicated on the horizontal axis and the augmented ice net ablation due to this perturbation is shown by arrows. The increase in ice net ablation varies along the profile between $300 \mathrm{~kg} \mathrm{~m}^{-2}$ $(\Delta h=0)$ and $750 \mathrm{~kg} \mathrm{~m}^{-2}(\Delta h=-600 \mathrm{~m})$. Assuming a constant slope along the profile, the averaged relative increase in net ice ablation amounts to $45 \%$.

\section{FINAL REMARKS}

Th extension of the perturbation analysis to the entire Greenland ice sheet is of speculative character, since the required data are broadly unknown. Equilibrium-line altitude, ablation area and climatological conditions vary considerably from one region to another. Therefore, it is proposed to subdivide the Greenland ice sheet into four climatic zones (Oerlemans, 1991; Oerlemans and others, in press).

The gradient $\partial c / \partial z$ is of decisive importance for the stability of the mass balance (Ambach, 1988). Negative values of $\partial c / \partial z$ which are significant for the sensitive response of the equilibrium line on the Greenland ice sheet have been reported by Benson (1962). Along a profile at $70^{\circ} \mathrm{N}$ between $2000 \mathrm{~m} \leq z \leq 3100 \mathrm{~m}$ a.s.l. the averaged value amounts to $\partial c / \partial z=-0.26 \mathrm{~kg} \mathrm{~m}^{-2} \mathrm{~m}^{-1}$, along a profile at $77^{\circ} \mathrm{N}$ between $1000 \mathrm{~m} \leq z$ $\leq 2100 \mathrm{~m}$ a.s.l. it amounts to $\partial c / \partial z=-0.32 \mathrm{~kg} \mathrm{~m}^{-2} \mathrm{~m}^{-1}$. The latter value is of particular importance since the 
present-day equilibrium line in the Thule area is situated only slightly below this range of altitude. When the equilibrium line is shifted by climatic warming into an area of negative values of $\partial c / \partial z$, the instability criterion becomes effective. In this case, the shift of the equilibrium line due to perturbations in temperature is significantly enlarged by a factor of 1.8 compared with the condition at the EGIG line.

With the perturbation $\delta T_{\mathrm{a}}=+1 \mathrm{~K}$, an increase of the net ice ablation of $45 \%$ was obtained at the EGIG line. If this figure is considered to be representative for the entire Greenland ice sheet, the annual increase of total net ablation results in $0.45 A_{0} \mathrm{~km}^{3}$ year $^{-1}$ water equivalent, where $A_{0}$ is the present annual total net ablation of the entire Greenland ice sheet. With $A_{0}=300 \mathrm{~km}^{3}$ year (Weidick, unpublished), the annual change in total net ablation amounts to $135 \mathrm{~km}^{3}$ year ${ }^{-1}$ water equivalent for $\delta T_{\mathrm{a}}=+1 \mathrm{~K}$. The related sea-level rise depends significantly on the share of refreezing of meltwater in the ablation area. If no refreezing occurs, the sea-level rise results in $0.37 \mathrm{~mm}_{\text {year }}{ }^{-1}$, which is the same figure obtained by Oerlemans and others (in press) by means of a more detailed analysis. A previous work by Ambach and Kuhn (1989) yielded a value of $0.34 \mathrm{~mm} \mathrm{year}^{-1}$. Bindschadler (1985) took into consideration the response of the ice margin, when a perfect plastic ice sheet is assumed. For two scenarios, the corresponding sea-level rise results in 0.40 and $0.54 \mathrm{~mm}$ year $^{-1}$. However, $\mathrm{a}^{\text {' }}$ considerable degree of uncertainty must be accepted.

Another criterion for the stability of the Greenland ice sheet is the condition, when the total net ablation $(A)$ equals the total net accumulation $(C)$. Neglecting possible refreezing of meltwater and applying data from the EGIG-line on to the entire Greenland ice sheet, the condition $A=C$ is fulfilled at a warming of $\delta T_{\mathrm{a}} \sim+2 \mathrm{~K}$ (Ambach and Kuhn, 1989). In this case, the surface balance is zero; due to continuous iceberg discharge, the shrinking of the Greenland ice sheet is accelerated. Even if some parameters in the model are varied, the condition $A=C$ results in between 1 and $3 \mathrm{~K}$ (Table 3 ). Thus, the Greenland ice sheet reacts very sensitively to climatic warming.

In view of a three-dimensional thermomechanic model applied by Huybrechts and others (1991), the run-off is increased by $40 \%$ (exactly $42 \%$ ) for $T_{\mathrm{a}}=+1 \mathrm{~K}$ as compared to $45 \%$ obtained in the present paper. The surface balance becomes negative for a warming above $+2.7 \mathrm{~K}$. This conclusion is in good agreement with the condition $A=C$ for $\delta T_{\mathrm{a}} \approx+2 \mathrm{~K}$, which is derived in the present paper. The entire Greenland ice sheet will disappear for $\delta T_{\mathrm{a}}=+6 \mathrm{~K}$ after 20000 years (Letréguilly and others, 1991a). Koerner (1989) described observational evidence for intensive melting of the Greenland ice sheet in the last interglacial, although, according to Reeh and others (1991) and Letréguilly and others (1991b), the summit of the central Greenland ice sheet seems to have survived the warm climate due to isostatic uplift.

\section{ACKNOWLEDGEMENTS}

The manuscript is part of a project, supported financially by the Österreichische Akademie der Wissenschaften, Vienna. The author would like to thank Mr J. Huber for his co-operation in the evaluation of the data.

\section{REFERENCES}

Ambach, W. 1963. Untersuchungen zum Energieumsatz in der Ablationszone des grönländischen Inlandeises (Camp IV-EGIG, 69 $40^{\prime} 05^{\prime \prime} \mathrm{N}, 49^{\circ} 37^{\prime} 58^{\prime \prime} \mathrm{W}$ ). Medd. Gronl., 174(4).

Ambach, W. 1974. The influence of cloudiness on the net radiation balance of a snow surface with high albedo. 7. Glaciol., 13(67), 73-84.

Table 3. Perturbations in temperature which yield the condition $A=C$, dependent upon various combinations of gradients $\partial c / \partial z$ and $\partial T_{\mathrm{a}} / \partial z$ as well as initial values $A_{0}, C_{0}$
$A_{0} \quad\left(\mathrm{~km}^{3}\right.$ year $^{-1}$ w.e. $)$
300
320
390
$C_{0} \quad\left(\mathrm{~km}^{3}\right.$ year $^{-1}$ w.e. $)$
500
600
620

$$
\begin{aligned}
& \partial c / \partial z=+0.55 \mathrm{~kg} \mathrm{~m}^{-2} \mathrm{~m}^{-1} \\
& \partial T_{\mathrm{a}} / \partial z=-0.0073 \mathrm{~K} \mathrm{~m}^{-1} \\
& \partial c / \partial z=+0.55 \mathrm{~kg} \mathrm{~m}^{-2} \mathrm{~m}^{-1} \\
& \partial T_{\mathrm{a}} / \partial z=-0.0057 \mathrm{~K} \mathrm{~m}^{-1} \\
& \partial c / \partial z=-0.32 \mathrm{~kg} \mathrm{~m}^{-2} \mathrm{~m}^{-1} \\
& \partial T_{\mathrm{a}} / \partial z=-0.0073 \mathrm{~K} \mathrm{~m}^{-1} \\
& \partial c / \partial z=-0.32 \mathrm{~kg} \mathrm{~m}^{-2} \mathrm{~m}^{-1} \\
& \partial T_{\mathrm{a}} / \partial z=-0.0057 \mathrm{~K} \mathrm{~m}^{-1}
\end{aligned}
$$


Ambach, W. 1985. Characteristics of the heat balance of the Greenland ice sheet for modelling. F. Glaciol., 31(107), 3-12.

Ambach, W. 1988. Instabilities of the equilibrium line altitude in Greenland by climatic warming. Eidg. Tech. Hochschule, Zürich. Versuchsanst. Wasserbau, Hydrol. Glaziol. Mitt., 94, 51-57.

Ambach, W. 1989. Effects of climatic perturbations on the surface-ablation regime of the Greenland ice sheet, West Greenland. 7. Glaciol., 35(121), 311-316.

Ambach, W. and M. Kuhn. 1989. Altitudinal shift of the equilibrium line in Greenland calculated from heat balance characteristics. In Oerlemans, J., ed. Glacier fluctuations and climatic change. Proceedings of the Symposium on Glacier Fluctuations and Climatic Change, held in Amsterdam, 1-5 June 1987. Dordrecht, etc., Kluwer Academic Publishers, 281-288.

Benson, C. S. 1962. Stratigraphic studies in the snow and firn of the Greenland ice sheet. SIPRE Res. Rep. 70.

Bindschadler, R. A. 1985. Contribution of the Greenland ice sheet to changing sea level: present and future. In United States Department of Energy. Glaciers, Ice Sheets, and Sea Levels: Effect of a $\mathrm{CO}_{2}$-induced Climatic Change. Report of a Workshop held in Seattle, Washington, September 13-15, 1984. Washington, DC, National Academy Press, 258-266.

Huybrechts, P., A. Letréguilly and N. Reeh. 1991. The Greenland ice sheet and greenhouse warming. Palaeogeogr. Palaeoclimatol. Palaeoecol., 89(4), 399-412.

Koerner, R. M. 1989. Ice core evidence for extensive melting of the Greenland ice sheet in the last interglacial. Science, 244(4907), 964-968.

Kuhn, M. 1981. Climate and glaciers. International Association of Hydrological Sciences Publication 131 (Symposium at Canberra 1979 - Sea Level, Ice and
Climatic Change), 3-20.

Letréguilly, A., P. Huybrechts and N. Reeh. 1991a. Steady-state characteristics of the Greenland ice sheet under different climates. F. Glaciol., 37(125), 149-157.

Letréguilly, A., P. Huybrechts and N. Reeh. 1991b. The Greenland ice sheet through the last glacier-interglacial cycle. Palaeogeogr. Palaeoclimatol. Palaeoecol., 90, 385-394.

Manabe, S. and R. T. Wetherald. 1975. The effects of doubling $\mathrm{CO}_{2}$-concentration on the climate of a general circulation model. F. Atmos. Sci., 32(1), 3-15.

Oerlemans, J. 1991. The mass balance of the Greenland ice sheet: sensitivity to climatic change as revealed by energy-balance modelling. Holocene, 1 (1), 40-49.

Oerlemans, J., R. S. W. van der Wal and L. A. Conrads. In press. A model for surface balance of ice masses. Part II. Application to the Greenland ice sheet. $Z$. Gletscherkd. Glazialgeol.

Reeh, N., H. Oerter, A. Letréguilly, H. Miller and H. W. Huberten. 1991. A new, detailed ice-age oxygen-18 record from the ice-sheet margin in central West Greenland. Palaeogeogr. Palaeoclimatol. Palaeoecol., 90, 373-383.

United States Department of Energy. 1985. Glaciers, Ice Sheets, and Sea Level: Effect of a $\mathrm{CO}_{2}$-induced Climatic Change. Report of a Workshop held in Seattle, Washington, September 13-15, 1984. Washington, DC, National Academy Press.

Weidick, A. Unpublished. Glacial history of Greenland: a review. Internationale Polartagung, October 4-7, 1978. Oral presentation.

The accuracy of references in the text and in this list is the responsibility of the author, to whom queries should be addressed. 